\title{
CrystEngComm
}

Cite this: CrystEngComm, 2014, 16, 5121

Received 20th January 2014, Accepted 26th March 2014

DOI: $10.1039 / c 4 c e 00145 a$

www.rsc.org/crystengcomm

\section{Copper-based coordination polymers from thiophene and furan dicarboxylates with high isosteric heats of hydrogen adsorption $\uparrow$}

\begin{abstract}
Jie Yang, ${ }^{\text {ab }}$ Martin Lutz, ${ }^{c}$ Anna Grzech, ${ }^{d}$ Fokko M. Mulder ${ }^{d}$ and Theo J. Dingemans ${ }^{\star b}$
Self-assembled $\mathrm{Cu}$-based coordination polymers derived from thiophene-2,5-dicarboxylic acid (Cu-TDC) and furan-2,5-dicarboxylic acid (Cu-FDC) were synthesized via a solvothermal method and their $\mathrm{H}_{2}$ adsorption behaviour was investigated and contrasted with isophthalic acid (Cu-m-BDC) and terephthalic acid (Cu-BDC) derivatives. Both heterocyclic-based coordination polymers exhibit low surface areas $\left(<300 \mathrm{~m}^{2} \mathrm{~g}^{-1}\right)$ upon activation but unusually high isosteric heats of hydrogen adsorption (7.5-9.2 $\left.\mathrm{kJ} \mathrm{mol}^{-1}\right)$. Hydrogen uptake values of $0.64-0.75 \mathrm{wt} \%$ (77 $\mathrm{K}$ and $1 \mathrm{bar}$ ) were recorded and these high uptake values are attributed to the optimal pore size (5.4-8 $\AA$ ) and the polarizability of the 5-membered heterocycles.
\end{abstract}

\section{Introduction}

Metal-organic coordination polymers are promising candidates for hydrogen storage, gas separation and optoelectronic applications. In these materials, polyfunctional organic ligands form coordination bonds with multiple metal atoms, which may extend into one-, two-, or three-dimensional polymeric structures., ${ }^{1,2}$ Benzenecarboxylic acids and nitrogenbased heterocyclic carboxylic acids have been well documented as useful building blocks for the construction of a wide variety of metal-organic coordination polymers. ${ }^{3}$ More interestingly, introducing oxygen- or sulphur-containing heterocycles would endow metal-organic coordination polymers with unique physical and chemical properties. ${ }^{4}$ To date, a systematic study on the hydrogen storage properties of heterocyclic-based metal-organic coordination polymers has not been reported.

Thiophene-2,5-dicarboxylic acid ( $\left.\mathrm{H}_{2} \mathrm{TDC}\right)$ and furan-2,5dicarboxylic acid $\left(\mathrm{H}_{2} \mathrm{FDC}\right)$ are two basic representatives of the

\footnotetext{
${ }^{a}$ College of Mathematics and Physics, Shanghai University of Electric Power, Shanghai, 200090, PR China

${ }^{b}$ Faculty of Aerospace Engineering, Delft University of Technology, Kluyverweg 1, Delft, The Netherlands. E-mail: t.j.dingemans@tudelft.nl; Fax: +31(0)152784472; Tel: $+31(0) 152784520$

${ }^{c}$ Crystal and Structural Chemistry, Bijvoet Center for Biomolecular Research Faculty of Science, Utrecht University, Padualaan 8, 3584 CH Utrecht, The Netherlands

${ }^{d}$ Department of Chemical Engineering, Faculty of Applied Sciences, Delft University of Technology, Mekelweg 15, 2629 JB Delft, The Netherlands. E-mail: f.m.mulder@tudelft.nl; Fax: +31(0)152783803; Tel: +31(0)152784870 $\dagger$ Electronic supplementary information (ESI) available: characterization data including X-ray crystal structures, TG curves and hydrogen isotherms. CCDC 956646-956648. For ESI and crystallographic data in CIF or other electronic format see DOI: 10.1039/c4ce00145a
}

heterocyclic dicarboxylic acid family. Owing to the larger radius of the $\mathrm{S}$ atom, as compared to $\mathrm{C}, \mathrm{N}$, and $\mathrm{O}$, its one pair of electrons can easily delocalize over the heterocyclic ring, and as a ligand thiophene-2,5-dicarboxylic acid exhibits good charge-transfer ability. Furan-2,5-dicarboxylic acid, on the other hand, is of interest for similar reasons but in particular because it is considered to be a bio-renewable building block in the formation of polymers from biomass. We have selected copper(II) as the cation because Jahn-Teller distortions will weaken the bonding of solvent molecules at the axial sites. The resulting open metal sites and the $\mathrm{Cu}^{\delta+}-\mathrm{O}^{\delta-}$ dipoles on the surface generated upon removal of these solvent molecules will result in an enhancement of the local interaction energy for hydrogen. ${ }^{5}$ In the present work, we have synthesized $\mathrm{Cu}$-based coordination polymers derived from thiophene-2,5-dicarboxylic acid ( $\mathrm{H}_{2}$ TDC) and furan-2,5dicarboxylic acid ( $\left.\mathrm{H}_{2} \mathrm{FDC}\right)$. $\mathrm{Cu}$-based coordination polymers based on terephthalic acid (Cu-BDC) and isophthalic acid (Cu-m-BDC) were also prepared as reference materials because they don't contain a transverse dipole moment and this series allows us to investigate the role of the exocyclic bond angle $(\theta)$ of the dicarboxylate linker shown in Scheme 1. Herein we report on the structural characteristics, stability and hydrogen storage properties of this series of Cu-based coordination polymers.
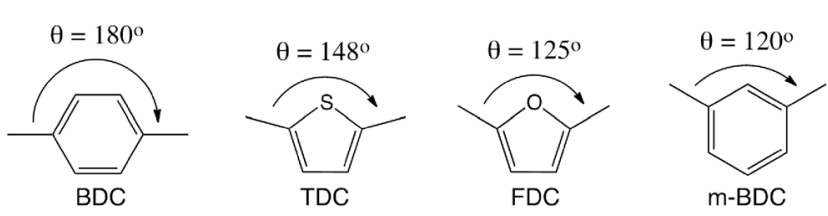

Scheme 1 The exocyclic bond angle $(\theta)$ of the dicarboxylate linker units. 


\section{Experimental}

\section{Materials}

$\mathrm{Cu}\left(\mathrm{NO}_{3}\right)_{2} \cdot 2.5 \mathrm{H}_{2} \mathrm{O}$ (Acros, 97\%), thiophene-2,5-dicarboxylic acid ( $\mathrm{H}_{2} \mathrm{TDC}$, George Uh4 Co., Inc.), furan-2,5-dicarboxylic acid $\left(\mathrm{H}_{2} \mathrm{FDC}\right.$, TCI, 98\%), isophthalic acid $\left(m-\mathrm{H}_{2} \mathrm{BDC}\right.$, Acros, $98 \%)$, terephthalic acid $\left(\mathrm{H}_{2} \mathrm{BDC}, \mathrm{BP},>99 \%\right), N, N^{\prime}$-dimethylformamide (DMF, Acros), chloroform $\left(\mathrm{CHCl}_{3}\right)$, absolute ethanol (EtOH), and benzene were used as received. Isophthalic acid was recrystallized from EtOH.

\section{Synthesis}

Synthesis of Cu-TDC. In a $20 \mathrm{~mL}$ vial, $23.7 \mathrm{mg}(0.10 \mathrm{mmol})$ of $\mathrm{Cu}\left(\mathrm{NO}_{3}\right)_{2} \cdot 2.5 \mathrm{H}_{2} \mathrm{O}$ and $23.0 \mathrm{mg}(0.13 \mathrm{mmol})$ of thiophene2,5-dicarboxylic acid were dissolved in $\mathrm{DMF} / \mathrm{H}_{2} \mathrm{O} / \mathrm{EtOH}$ $(1.5 \mathrm{~mL} / 0.25 \mathrm{~mL} / 0.5 \mathrm{~mL})$. The vial was placed into a preheated oven and kept at $80{ }^{\circ} \mathrm{C}$ for $24 \mathrm{~h}$. Blue crystals were collected and washed with DMF and $\mathrm{EtOH}$, then vacuum dried overnight at $25{ }^{\circ} \mathrm{C}$. The product $(23.5 \mathrm{mg})$ was labeled $\mathrm{Cu}$-TDC and stored in a glove box.

Synthesis of Cu-FDC. In a $20 \mathrm{~mL}$ vial, $22.3 \mathrm{mg}(0.096 \mathrm{mmol})$ of $\mathrm{Cu}\left(\mathrm{NO}_{3}\right)_{2} \cdot 2.5 \mathrm{H}_{2} \mathrm{O}$ and $21.4 \mathrm{mg}(0.14 \mathrm{mmol})$ of furan-2,5dicarboxylic acid were dissolved in $\mathrm{DMF} / \mathrm{H}_{2} \mathrm{O} / \mathrm{EtOH}(1.5 \mathrm{~mL} /$ $0.5 \mathrm{~mL} / 0.5 \mathrm{~mL}$ ). The vial was placed into a preheated oven and kept at $80{ }^{\circ} \mathrm{C}$ for $24 \mathrm{~h}$. Blue crystals were filtered and washed with DMF and EtOH, then vacuum dried overnight at $25^{\circ} \mathrm{C}$. The product $(25.0 \mathrm{mg})$ was labeled $\mathrm{Cu}-\mathrm{FDC}$ and stored in a glove box.

Synthesis of Cu-BDC. $0.6958 \mathrm{~g}(3.0 \mathrm{mmol})$ of $\mathrm{Cu}\left(\mathrm{NO}_{3}\right)_{2} \cdot 2.5 \mathrm{H}_{2} \mathrm{O}$ and $0.4979 \mathrm{~g}$ of terephthalic acid $(3.0 \mathrm{mmol})$ were dissolved in $60 \mathrm{~mL}$ of DMF. The solution was placed in a preheated oven at $110{ }^{\circ} \mathrm{C}$ for $36 \mathrm{~h}$. The product was collected as a blue powder and washed with DMF $(2 \times 30 \mathrm{~mL})$, followed by heating at $60{ }^{\circ} \mathrm{C}$ under vacuum overnight. The product $(0.54 \mathrm{~g})$ was labeled Cu-BDC and stored in a glove box.

Synthesis of Cu-m-BDC. $0.5598 \mathrm{~g}$ ( $3.37 \mathrm{mmol})$ of isophthalic acid and $0.7601 \mathrm{~g}(3.27 \mathrm{mmol})$ of $\mathrm{Cu}\left(\mathrm{NO}_{3}\right)_{2} \cdot 2.5 \mathrm{H}_{2} \mathrm{O}$ were dissolved in a mixed solution of DMF-EtOH $(60 \mathrm{~mL} / 20 \mathrm{~mL})$. The solution was placed into a preheated oven at $80^{\circ} \mathrm{C}$ for $24 \mathrm{~h}$. The blue crystals were washed with DMF-EtOH mixture $(3: 1)(3 \times 20 \mathrm{~mL})$ and dried at r.t. under vacuum for $7 \mathrm{~h}$. The product $(0.42 \mathrm{~g})$ was labeled $\mathrm{Cu}-\mathrm{m}$-BDC and stored in a glove box.

Activation. The samples were activated using the following methods. A - $\mathrm{CHCl}_{3}$-exchange $\left(\mathrm{SE}\left(\mathrm{CHCl}_{3}\right)\right)$ : under an inert atmosphere, $\mathrm{Cu}$-TDC was extracted three times with fresh $\mathrm{CHCl}_{3}(2 \mathrm{~mL}$ for $15 \mathrm{~h}, 2 \mathrm{~mL}$ for $9 \mathrm{~h}, 2 \mathrm{~mL}$ for $15 \mathrm{~h}$ ) and dried under vacuum at room temperature overnight and at $60{ }^{\circ} \mathrm{C}$ for 3 days. The activated samples were denoted as Cu-TDC$\mathrm{SE}\left(\mathrm{CHCl}_{3}\right)$. The $\mathrm{CHCl}_{3}$-exchange was also employed for activating the $\mathrm{Cu}-\mathrm{FDC}$ and $\mathrm{Cu}-m$-BDC samples. The resulting samples were denoted as $\mathrm{Cu}-\mathrm{FDC}-\mathrm{SE}\left(\mathrm{CHCl}_{3}\right)$ and $\mathrm{Cu}-m$-BDC$\mathrm{SE}\left(\mathrm{CHCl}_{3}\right)$, respectively. B - EtOH-exchange (SE(EtOH)): under an inert atmosphere, $200 \mathrm{mg}$ of $\mathrm{Cu}-m$-BDC or $\mathrm{Cu}-\mathrm{BDC}$ was extracted two times with absolute EtOH $(20 \mathrm{~mL}$ for $15 \mathrm{~h}, 20 \mathrm{~mL}$ for $14 \mathrm{~h}$ ) and dried under vacuum at room temperature overnight and at $45{ }^{\circ} \mathrm{C}$ for $20 \mathrm{~h}$. The activated samples were denoted as $\mathrm{Cu}-m$-BDC-SE(EtOH) and Cu-BDC-SE(EtOH), respectively. C - Freeze-drying (FD): about $400 \mathrm{mg}$ of a fresh sample was placed in a Schlenk tube and washed with $\mathrm{CH}_{2} \mathrm{Cl}_{2}(10 \mathrm{~mL} \times 3)$ and benzene $(8 \mathrm{~mL} \times 2)$, followed by immersing in $10 \mathrm{~mL}$ of benzene overnight. The tube was placed into an ice-water bath $\left(0^{\circ} \mathrm{C}\right)$. After three freeze-thaw cycles, the sample was evacuated in an ice-water bath for $24 \mathrm{~h}$. The sample was kept under vacuum at room temperature for $24 \mathrm{~h}$ and at $60{ }^{\circ} \mathrm{C}$ for $24 \mathrm{~h}$. The samples activated via this freeze-drying process were labeled $\mathrm{Cu}$-TDC-FD, Cu-FDC-FD and $\mathrm{Cu}-m$-BDC-FD.

\section{Characterization}

Single-crystal X-ray structure determination of Cu-TDC. $\mathrm{C}_{9} \mathrm{H}_{9} \mathrm{CuNO}_{5} \mathrm{~S}+$ disordered solvent, $\mathrm{Fw}=306.77$. Sample appearance and dimensions: blue block, $0.41 \times 0.39 \times 0.26 \mathrm{~mm}^{3}$. Trigonal, $R \overline{3} c$ (no. 167), $a=b=20.0402(6), c=41.6541(13) \AA$, $V=14487.5(8) \AA^{3}, Z=36, D_{x}=1.266 \mathrm{~g} \mathrm{~cm}^{-3},+\mu=1.49 \mathrm{~mm}^{-1}+$ 62951 reflections were measured on a Bruker Kappa ApexII diffractometer with a sealed tube and a Triumph monochromator $(\lambda=0.71073 \AA)$ up to a resolution of $(\sin \theta / \lambda)_{\max }=0.65 \AA^{-1}$ at a temperature of $150(2) \mathrm{K}$. Intensity data were integrated using the SAINT software. ${ }^{6}$ Absorption correction and scaling were performed based on multiple measured reflections using SADABS (0.65-0.75 correction range). ${ }^{7} 3715$ reflections were unique $\left(R_{\text {int }}=0.026\right)$, of which 2649 were observed $[I>2 \sigma(I)]$. The structure was solved with direct methods using the program SHELXS-97 and refined with SHELXL-97 against $F^{2}$ of all reflections. ${ }^{8}$ Non-hydrogen atoms were refined with anisotropic displacement parameters. Hydrogen atoms were introduced in calculated positions and refined with a riding model. The crystal structure contains solvent accessible voids (5441 $\AA^{3}$ per unit cell) filled with disordered solvent molecules. Their contribution to the structure factors was secured by back-Fourier transformation using the SQUEEZE routine in PLATON resulting in 1482 electrons per unit cell. ${ }^{9}$ The $N, N^{\prime}$-dimethylformamide ligand was refined with a disorder model. 182 parameters were refined with 54 restraints (concerning the disordered DMF). $R_{1} / \mathrm{w} R_{2}[I>2 \sigma(I)]$ : $0.0367 / 0.1204$. $R_{1} / \mathrm{w} R_{2}$ (all refl.): 0.0473/0.1281. $S=1.141$. Residual electron density is between -0.47 and 0.49 e $\AA^{-3}$. Geometry calculations and checking for higher symmetry were performed using the PLATON program. ${ }^{9}$

Single-crystal X-ray structure determination of Cu-FDC. $\mathrm{C}_{18} \mathrm{H}_{12} \mathrm{Cu}_{3} \mathrm{O}_{18}+$ disordered solvent, $\mathrm{Fw}=706.90 . \S$ Sample appearance and dimensions: blue needle, $0.40 \times 0.15 \times$ $0.14 \mathrm{~mm}^{3}$. Monoclinic, $C 2 / m$ (no. 12), $a=18.9198(11), b=$ 18.8335(14), $c=12.6671(8) \AA, \beta=92.396(3)^{\circ}, V=4509.7(5) \AA^{3}$, $Z=4, D_{x}=1.041 \mathrm{~g} \mathrm{~cm}^{-3}, \S \mu=1.45 \mathrm{~mm}^{-1} . \S 75193$ reflections

$¥$ Derived values do not include the contribution of the disordered solvent molecules.

$\S$ Derived values do not include the contribution of the disordered solvent molecules. 
were measured on a Bruker Kappa ApexII diffractometer with a sealed tube and a Triumph monochromator $(\lambda=0.71073 \AA)$ up to a resolution of $(\sin \theta / \lambda)_{\max }=0.65 \AA^{-1}$ at a temperature of $150(2) \mathrm{K}$. The crystal was non-merohedrally twinned with a twofold rotation about $u v w=[-1,-1,2]$ as a twin operation. Intensity data were integrated using the Eval14 software $^{10}$ taking the twin relation into account. Absorption correction, scaling, and de-twinning were performed based on multiple measured reflections using TWINABS $^{7}(0.65-0.75$ correction range). 5351 reflections were unique $\left(R_{\text {int }}=0.040\right)$, of which 4804 were observed $[I>2 \sigma(I)]$. The structure was solved with direct methods using the program SHELXS-97 and refined with SHELXL-97 against $F^{2}$ of all reflections. ${ }^{8}$ Non-hydrogen atoms were refined with anisotropic displacement parameters. Hydrogen atoms were introduced in calculated positions and refined with a riding model. The crystal structure contains solvent accessible voids $\left(2650 \AA^{3}\right.$ per unit cell) filled with disordered solvent molecules. Their contribution to the structure factors was secured by back-Fourier transformation using the SQUEEZE routine in PLATON resulting in 838 electrons per unit cell. ${ }^{9} 181$ parameters were refined with no restraints. $R_{1} / \mathrm{w} R_{2}[I>2 \sigma(I)]: 0.0320 / 0.0835 . R_{1} / \mathrm{w} R_{2}$ (all refl.): 0.0354/0.0850. $S=1.040$. Residual electron density is between

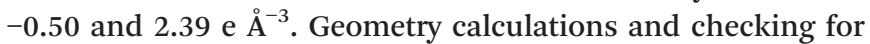
higher symmetry were performed using the PLATON program. ${ }^{9}$

Single-crystal X-ray structure determination of Cu- $m$-BDC. $\mathrm{C}_{222} \mathrm{H}_{166} \mathrm{Cu}_{24} \mathrm{~N}_{10} \mathrm{O}_{120}+$ disordered solvent, $\mathrm{Fw}=6418.60 .9$ Sample appearance and dimensions: blue needle, $0.40 \times$ $0.16 \times 0.15 \mathrm{~mm}^{3}$. Triclinic, $P \overline{1}$ (no. 2), $a=21.4985(13), b=$ 24.7145(14), $c=24.8218(14) \AA, \alpha=110.166(4), \beta=112.898(3)$, $\gamma=102.544(2)^{\circ}, V=10420.7(11) \AA^{3}, Z=1, D_{x}=1.023 \mathrm{~g} \mathrm{~cm}^{-3}$, $\mu=1.26 \mathrm{~mm}^{-1}$. 86010 reflections were measured on a Bruker Kappa ApexII diffractometer with a sealed tube and a Triumph monochromator $(\lambda=0.71073 \AA)$ up to a resolution of $(\sin \theta / \lambda)_{\max }=0.56 \AA^{-1}$ at a temperature of $150(2) \mathrm{K}$. Intensity data were integrated using the Eval15 software. ${ }^{11}$ Absorption correction and scaling were performed based on multiple measured reflections using SADABS $^{7}(0.66-0.74$ correction range). 30432 reflections were unique $\left(R_{\text {int }}=0.038\right)$, of which 20697 were observed $[I>2 \sigma(I)]$. The structure was solved using the program SHELXT and refined with SHELXL-2013 against $F^{2}$ of all reflections. ${ }^{8}$ Non hydrogen atoms of the framework were refined with anisotropic displacement parameters. Coordinated solvent molecules (DMF, $\mathrm{H}_{2} \mathrm{O}$ ) were disordered on the same coordination site and were refined with isotropic displacement parameters. Hydrogen atoms were introduced in calculated positions and refined with a riding model. Hydrogen atoms of the water molecules were omitted. The crystal structure contains solvent accessible voids (4443 $\AA^{3}$ per unit cell) filled with disordered solvent molecules. Their contribution to the structure factors was secured by back-Fourier transformation using the SQUEEZE routine in PLATON resulting in 1069 electrons per

9 Derived values do not include the contribution of the disordered solvent molecules. They also do not include the $\mathrm{H}$ atoms of the water molecules. unit cell. ${ }^{9} 1613$ parameters were refined with 190 restraints (concerning disordered DMF). $R_{1} / \mathrm{w} R_{2}[I>2 \sigma(I)]: 0.0712 / 0.2220$. $R_{1} / \mathrm{w} R_{2}$ (all refl.): 0.0969/0.2456. $S=1.057$. Residual electron

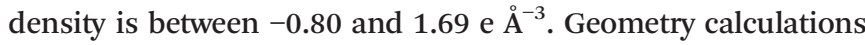
and checking for higher symmetry were performed using the PLATON program. ${ }^{9}$

\section{Powder XRD, elemental analysis, TGA, BET, and $\mathrm{H}_{2}$ adsorption}

XRD patterns of all samples were recorded using an X'Pert X-ray diffractometer operated at $45 \mathrm{kV}$ and $40 \mathrm{~mA}$ with monochromatic $\mathrm{Cu} \mathrm{K} \alpha$ radiation within a 2 -theta range of $5-60^{\circ}$. IR spectra were collected using a PerkinElmer Spectrum 100 FT-IR Spectrometer. Elemental analyses were performed using a Thermo Scientific InterScience Flash 2000 Organic Elemental Analyzer. TGA curves were obtained using a PerkinElmer Pyris Diamond Thermogravimetric Differential Thermal/Analyzer. Samples were heated from room temperature to $600{ }^{\circ} \mathrm{C}$ with a heating rate of $10{ }^{\circ} \mathrm{C} \mathrm{min}$ min $^{-1}$ under a dry air flow. The pore textural properties, including the BET surface area and pore volume, were recorded using a Micromeritics ASAP 2010 adsorption analyser at $77 \mathrm{~K}$. Prior to the adsorption measurements, the samples were degassed in situ under vacuum at $50{ }^{\circ} \mathrm{C}$ (for the samples activated by solventexchange) or at $80{ }^{\circ} \mathrm{C}$ (for the samples activated by freezedrying) overnight. The dead volume of the sample cell was determined in a separate experiment. In situ pretreatment coupled to a separate dead volume measurement after the analysis was employed in order to avoid the helium entrapment phenomenon. The weight of a sample obtained after the pretreatment was used in various calculations. BET surface areas were calculated in the adapted pressure range of $P / P_{0}=0.01-0.1$. Hydrogen storage measurements in the low-pressure range $(<2$ bar) were performed on a Sievert's setup at $77 \mathrm{~K}$ and $100 \mathrm{~K}$. Prior to the measurement, the samples activated by solvent-exchange were pretreated under high vacuum $\left(10^{-6} \mathrm{mbar}\right)$ at $25{ }^{\circ} \mathrm{C}$ for 1 day. The samples activated by freeze-drying were pretreated under high vacuum $\left(10^{-6} \mathrm{mbar}\right)$ at $80{ }^{\circ} \mathrm{C}$ for 1 day. Hydrogen (ultra-high-purity grade, $99.999 \%$ ) was additionally purified by leading it over a bed of zeolite spheres at $77 \mathrm{~K}$ before being loaded onto the samples. The pressure change was monitored and recorded after the hydrogen reservoir was connected to the sample holder. The samples were weighed in a glove box after the measurements for calculating the hydrogen uptake capacities. The amount of hydrogen stored in the dead volume was examined using sea sand as a reference. The hydrogen uptake capacities of all samples were obtained by subtracting the amount of hydrogen in the dead volume from the total amount of hydrogen released from the reservoir.

\section{Results and discussion}

\section{Crystal structures}

The structures of Cu-TDC (Fig. S1-S6 and Table S1-S3†),

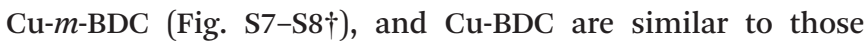


reported before. ${ }^{12-14}$ Their detailed structures were described in the ESI $\uparrow{ }^{15}$

The new Cu-based coordination polymer composed of furan-2,5-dicarboxylate $\left(\mathrm{Cu}(\mathrm{FDC})\left(\mathrm{H}_{2} \mathrm{O}\right)\right)$ crystallizes in the monoclinic space group $C 2 / m$ (no. 12) with one Cu-center on a mirror plane and one $\mathrm{Cu}$-center on a general position. The asymmetric unit contains $1.5 \mathrm{Cu}^{2+}$ ions, 1.5 FDC ligands and 1.5 coordinated $\mathrm{H}_{2} \mathrm{O}$ molecules (Fig. 1). $\mathrm{Cu} 1$ and water oxygen $\mathrm{O} 1$ are located on the mirror plane $x, 0.5, z$ and oxygen $\mathrm{O} 5$ of a FDC ligand is located on the mirror plane $x$, $0, z$. Due to the deprotonation of all carboxylates the FDC ligands are dianionic. The carboxylate groups are bridging two copper ions into a $\mathrm{Cu}_{2} \mathrm{O}_{8} \mathrm{C}_{4}$ unit, which is similar to that in $\mathrm{Cu}$-TDC. Because of the lower symmetry than that in $\mathrm{Cu}$-TDC, there are two independent $\mathrm{Cu}_{2} \mathrm{O}_{8} \mathrm{C}_{4}$ units with $C_{2 \mathrm{~h}}$ and $C_{\mathrm{i}}$ symmetry, respectively, and the $\mathrm{Cu}-\mathrm{Cu}$ distances in Cu-FDC are 2.6518(6) and 2.6782(5) A. A simplified representation of the cluster is shown in Fig. S9. $\uparrow$ There are four carboxylate bridges for every $\mathrm{Cu}_{2}$ unit. In the $\mathrm{Cu}$-FDC structure, the sixth coordinated position at each $\mathrm{Cu}$ ion is occupied by a water molecule. The $\mathrm{Cu}-\mathrm{O}$ distances of the water ligands are longer than the carboxylate distances. Both independent $\mathrm{Cu}$ centers are in distorted octahedral environments. Selected bond distances and angles are given in Table S4. $\dagger$

The furan cores of the FDC ligands link the $\mathrm{Cu}_{2}$ dimers into an infinite two-dimensional network in the crystallographic $(2,0,1)$ plane (Fig. 2). The $\mathrm{Cu}$ ions occupy the corners of triangles. The $\mathrm{Cu} \cdots \mathrm{Cu}$ distances between the corners vary

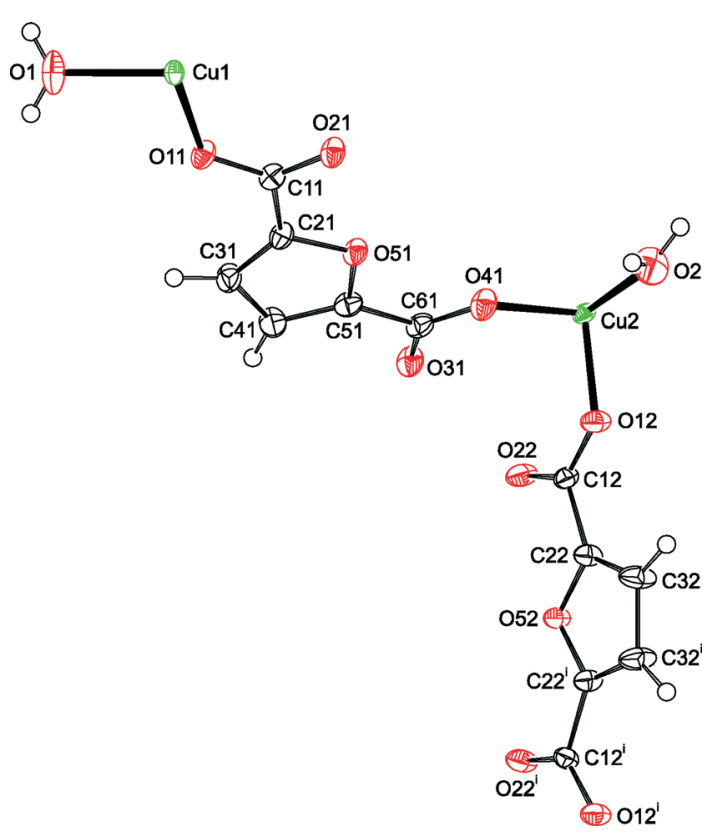

Fig. 1 An asymmetric unit of the crystal structure of Cu-FDC viewed along the crystallographic $c$-axis. Displacement ellipsoids are drawn at the $50 \%$ probability level. Atoms Cu1, O1, and $\mathrm{O} 52$ are located on crystallographic mirror planes. Non-coordinated solvent molecules were treated as diffuse electron density (see Experimental section) and were omitted in the drawing. Symmetry operation $i: x,-y, z$.

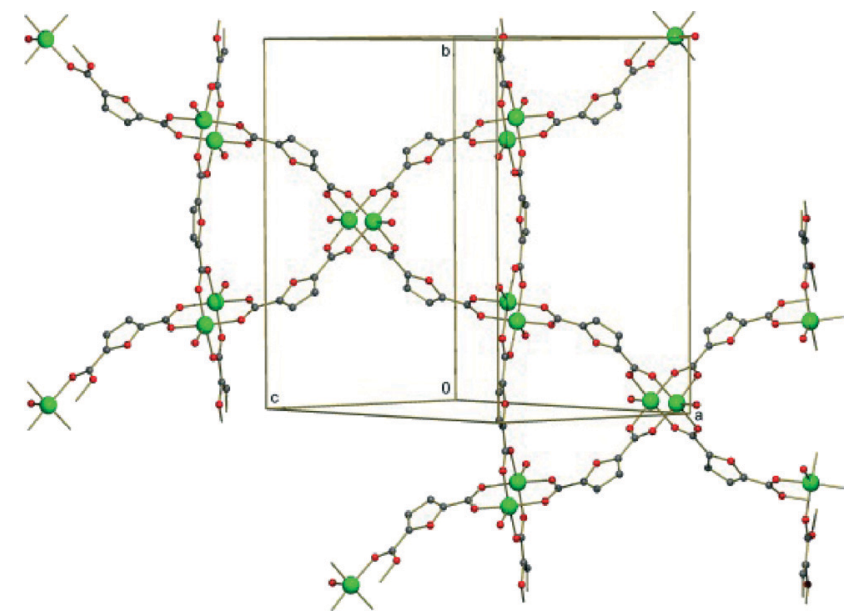

Fig. 2 An infinite two-dimensional coordination layer in the crystal structure of $\mathrm{Cu}-\mathrm{FDC}$. Hydrogen atoms are omitted for clarity.

between $8.2732(7)$ for $\mathrm{Cu} 2 \cdots \mathrm{Cu} 1^{i}$ and $10.5170(8) \AA$ for $\mathrm{Cu} 2 \cdots \mathrm{Cu} 2^{v}(i:-x, y, 1-z ; v: x,-y, z)$.

Cu-FDC contains coordinated water molecules, which can act as hydrogen bond donors. The acceptors for these hydrogen bonds are not part of the framework structure but are located in the solvent area. In the framework there is only one weak $\mathrm{C}-\mathrm{H} \cdots \mathrm{O}$ hydrogen bond linking the stacked $2 \mathrm{D}$ layers. Furan carbon atom C32 is the donor of the hydrogen bond and carboxylate oxygen $\mathrm{O} 11$ is the acceptor (Fig. 3 and Table S5 $\dagger$ ).

The crystal structure of Cu-FDC contains large solvent accessible voids. PLATON calculates a volume percentage of $\sim 58 \%$ for these voids (Fig. 4 ).

The exocyclic angles of $m-\mathrm{H}_{2} \mathrm{BDC}, \mathrm{H}_{2} \mathrm{FDC}, \mathrm{H}_{2}$ TDC, and $\mathrm{H}_{2} \mathrm{BDC}$ are $120^{\circ}, 125^{\circ}, 148^{\circ}$ and $180^{\circ}$, respectively. Except for $m-\mathrm{H}_{2} \mathrm{BDC}$, the diacids $\mathrm{H}_{2}$ TDC, $\mathrm{H}_{2}$ FDC and $\mathrm{H}_{2}$ BDC react with $\mathrm{Cu}$ ions and form structures with similar architectures. It seems that the exocyclic angle is in fact not very critical in terms of determining the structural architecture of this class of $\mathrm{Cu}$-base coordination polymers.

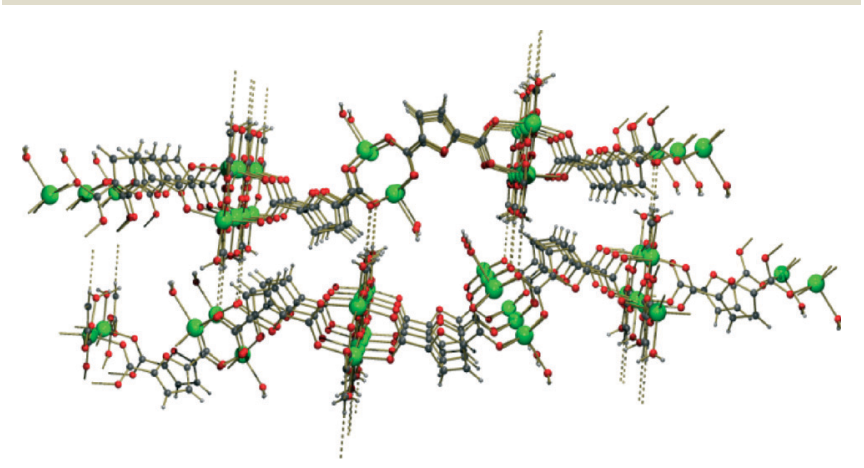

Fig. 3 Weak $\mathrm{C}-\mathrm{H} \cdots \mathrm{O}$ hydrogen bonding in the crystal structure of $\mathrm{Cu}$-FDC viewed along the crystallographic $b$-axis. Two-dimensional coordination planes are shown horizontally. Hydrogen bonds are shown as dashed lines. 


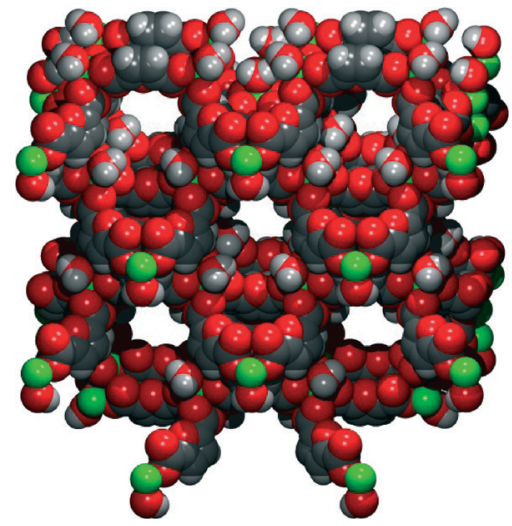

Fig. 4 The space filling plot of the crystal structure of Cu-FDC.

\section{Structural stability}

All Cu-samples (Cu-BDC, Cu-TDC, Cu-FDC and $\mathrm{Cu}-m$-BDC) were activated to remove the guest solvent molecules (DMF, ethanol and water) occupying the cavities before exploring their hydrogen storage properties. Cu-TDC, Cu-FDC and $\mathrm{Cu}-m$-BDC were activated via two methods: solvent-exchange (SE, solvents used: $\mathrm{CHCl}_{3}$ or EtOH) and freeze-drying (FD). Cu-BDC was activated by heating at $225{ }^{\circ} \mathrm{C}(\mathrm{H} 225)^{14}$ or by solvent-exchange (EtOH as a solvent). The activated samples were characterized by IR (Fig. S10 $\dagger$ ), element analysis, thermogravimetric analysis (Fig. S11 $\dagger$ ) and PXRD (Fig. 5). The TG curves of all four samples reveal that they decompose at about $300{ }^{\circ} \mathrm{C}$ (Fig. S10 $\dagger$ ). The PXRD results show that the structural stability of the resulting coordination polymers is strongly dependent on the activation method used. The
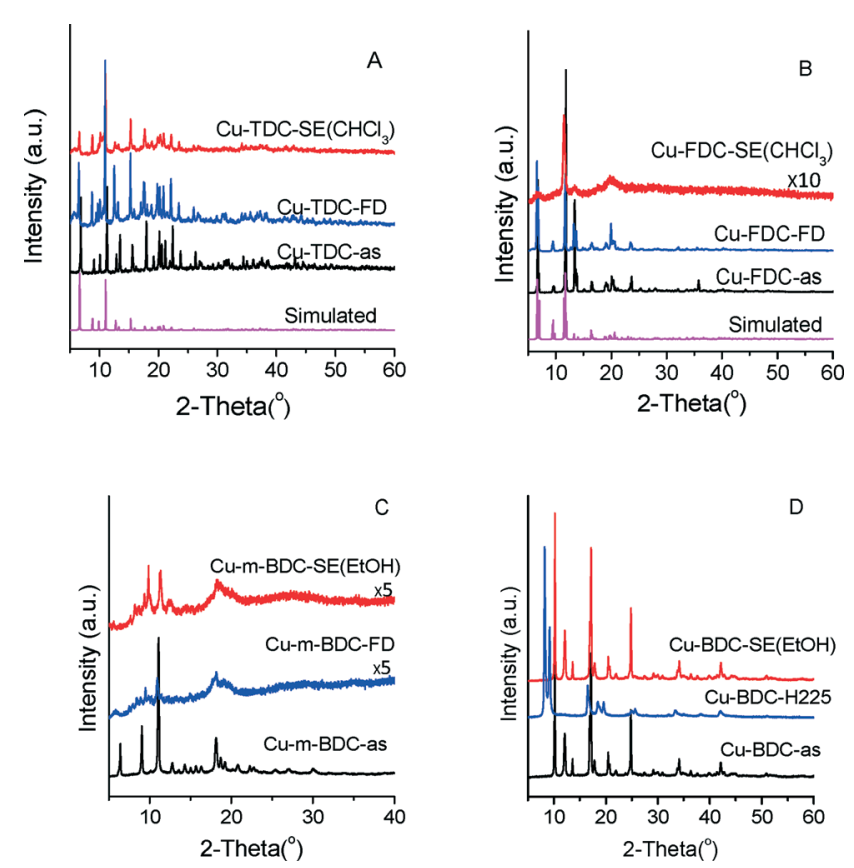

Fig. 5 PXRD patterns of the as prepared and activated Cu-TDC (A), $\mathrm{Cu}-\mathrm{FDC}$ (B), Cu-m-BDC (C) and Cu-BDC (D). structures of $\mathrm{Cu}$-TDC and $\mathrm{Cu}-\mathrm{FDC}$ were retained after freezedrying, which was confirmed by PXRD. However, poor PXRD patterns for $\mathrm{Cu}$-TDC-SE( $\left(\mathrm{CHCl}_{3}\right)$ and $\mathrm{Cu}$-FDC-SE $\left(\mathrm{CHCl}_{3}\right)$ were observed, revealing that $\mathrm{CHCl}_{3}$-exchange destabilized the $\mathrm{Cu}$-TDC structure and even destroyed the structure of $\mathrm{Cu}-\mathrm{FDC}$ (Fig. 5A and B). The PXRD results indicate that both $\mathrm{CHCl}_{3}$-exchange and freeze-drying did not work on the activation of $\mathrm{Cu}-m$-BDC. We also tried ethanol as a solvent to activate $\mathrm{Cu}-m$-BDC but this appeared unsuccessful as well (Fig. 5C). This suggests that the structure of $\mathrm{Cu}-m$-BDC is unstable during the process of removing the guest molecules from the cavities. For Cu-BDC a phase transformation was observed when heated at $225^{\circ} \mathrm{C}$ for $22 \mathrm{~h}$, which was confirmed by a different PXRD pattern of Cu-BDC-H225. The structure of $\mathrm{Cu}$-BDC remained intact when the EtOH-exchange method was used (Fig. 5D).

The Cu-TDC and Cu-FDC model structures resulting from single crystal diffraction experiments yield simulated powder diffraction patterns, which show the main reflections and reflection positions that are visible in the powder diffraction pattern of the as prepared samples (Fig. 5A and B). This confirms the structure of the as prepared materials. Deviations in peak intensities of the modeled structures and the experimental ones result from (anisotropic) motions of the linker molecules and from the adsorbed gasses or solvent remaining in the pores. The as measured and simulated XRD patterns for Cu-TDC and Cu-FDC are available in the ESI $\dagger$ in a larger format (Fig. S12).

\section{Hydrogen adsorption}

Because Cu-BDC-H225, Cu-BDC-SE(EtOH), Cu-TDC-FD, $\mathrm{Cu}-\mathrm{FDC}-\mathrm{FD}$ and $\mathrm{Cu}-m$-BDC-SE(EtOH) form stable structures upon activation, their hydrogen storage properties were investigated on a Sievert's setup at $77 \mathrm{~K}$ and below 1.5 bar and the results are shown in Fig. 6 and listed in Table 1. Cu-BDC-H225 showed a hydrogen uptake capacity of $1.22 \mathrm{wt} \%$ at $77 \mathrm{~K}$ and 1 bar, which is the highest hydrogen uptake among this series. Cu-TDC-FD and Cu-FDC-FD showed hydrogen uptake

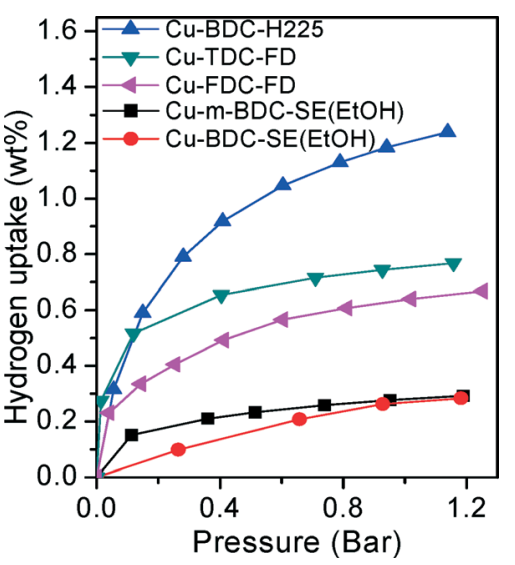

Fig. 6 The low-pressure hydrogen adsorption isotherms of activated Cu-BDC, Cu-TDC, Cu-FDC and Cu- $m$-BDC. 
Table 1 The chemical composition, textural properties, $\mathrm{H}_{2}$ uptake, and isosteric heat of $\mathrm{H}_{2}$ adsorption of the activated Cu-based coordination polymers

\begin{tabular}{|c|c|c|c|c|c|c|c|}
\hline Sample & $\mathrm{C}(\%)$ & $\mathrm{H}(\%)$ & $\mathrm{N}(\%)$ & $\begin{array}{l}\mathrm{SSA}_{\mathrm{BET}} \\
\left(\mathrm{m}^{2} \mathrm{~g}^{-1}\right)\end{array}$ & $\begin{array}{l}V_{\mathrm{p}} \\
\left(\mathrm{cm}^{3} \mathrm{~g}^{-1}\right)\end{array}$ & $\begin{array}{l}\mathrm{H}_{2} \text { uptake }^{a} \\
(\mathrm{wt} \%)\end{array}$ & $\begin{array}{l}\text { Isosteric heat of } \mathrm{H}_{2} \\
\text { adsorption }\left(\mathrm{kJ} \mathrm{mol}^{-1}\right)\end{array}$ \\
\hline Cu- $m$-BDC-SE(EtOH) & $38.5(41.5)$ & $3.35(2.59)$ & $1.19(2.18)$ & 13 & 0.03 & 0.28 & 3.0 \\
\hline $\mathrm{Cu}-\mathrm{TDC}-\mathrm{FD}$ & $32.9(35.2)$ & $3.10(2.94)$ & $4.10(4.57)$ & 308 & 0.16 & 0.75 & 9.2 \\
\hline Cu-BDC-H225 & $39.6(47.3)$ & $2.33(3.66)$ & $0.23(4.66)$ & 248 & 0.17 & 1.22 & 7.0 \\
\hline Cu-BDC-SE(EtOH) & $\mathrm{n} / \mathrm{a}$ & $\mathrm{n} / \mathrm{a}$ & $\mathrm{n} / \mathrm{a}$ & 8.7 & 0.01 & 0.27 & 2.2 \\
\hline
\end{tabular}

${ }^{a} 77 \mathrm{~K}$ and 1 bar; The values in brackets are the calculated C-, $\mathrm{H}-$, and $\mathrm{N}$-values based on the structural formula determined by single crystal $\mathrm{X}$-ray diffraction.

capacities of $0.75 \mathrm{wt} \%$ and $0.64 \mathrm{wt} \%$ at $77 \mathrm{~K}$ and 1 bar, respectively. $\mathrm{Cu}$-BDC-ES(EtOH) and $\mathrm{Cu}-m$-BDC-ES(EtOH) displayed comparable hydrogen storage capacities at $77 \mathrm{~K}$ and 1 bar $(0.27 \mathrm{wt} \%$ for Cu-BDC-ES(EtOH) and $0.28 \mathrm{wt} \%$ for $\mathrm{Cu}-m$-BDC-ES(EtOH)). The $\mathrm{H}_{2}$ uptake experiments were repeated 3 times for each sample and the uptake was found to be reversible (Fig. $\mathrm{S} 13 \dagger$ ).

The low hydrogen uptake capacities of $\mathrm{Cu}-m$-BDC-SE(EtOH) and $\mathrm{Cu}-\mathrm{BDC}-\mathrm{SE}(\mathrm{EtOH})$ can be explained by their poor porous structures (BET surface area $<15 \mathrm{~m}^{2} \mathrm{~g}^{-1}$ and pore volume $\left.<0.05 \mathrm{~cm}^{3} \mathrm{~g}^{-1}\right)$. The BET surface areas and the pore volumes of $\mathrm{Cu}-\mathrm{TDC}-\mathrm{FD}, \mathrm{Cu}-\mathrm{FDC}-\mathrm{FD}$ and $\mathrm{Cu}-\mathrm{BDC}-\mathrm{H} 225$ are in the range of 248-310 $\mathrm{m}^{2} \mathrm{~g}^{-1}$ and $0.16-0.21 \mathrm{~cm}^{3} \mathrm{~g}^{-1}$, respectively (Table 1 ). A BET surface area of $\sim 300 \mathrm{~m}^{2} \mathrm{~g}^{-1}$ has to be considered very low as compared to most other physisorbents used for hydrogen storage applications and indicates a poor porous structure. Compared with MOF-5, which has a BET surface area of $\sim 3000 \mathrm{~m}^{2} \mathrm{~g}^{-1}$, ${ }^{16}$ the BET surface areas of $\mathrm{Cu}-\mathrm{BDC}-\mathrm{H} 225$, $\mathrm{Cu}-\mathrm{TDC}-\mathrm{FD}$ and Cu-FDC-FD are only one tenth of MOF-5, whereas the hydrogen uptake capacity of $\mathrm{Cu}-m-\mathrm{BDC}-\mathrm{H} 225$ at $77 \mathrm{~K}$ and 1 bar is comparable to that of MOF-5 and the hydrogen uptake capacities of Cu-TDC-FD and Cu-FDC-FD at $77 \mathrm{~K}$ and 1 bar are about two-thirds that of MOF-5. This indicates that $\mathrm{Cu}$-based metal-organic coordination polymers show a good hydrogen uptake behaviour despite their low surface areas. Moreover, a rapid increase in the hydrogen uptake capacities of Cu-BDC-H225, Cu-TDC-FD and Cu-FDC-FD at low pressures ( $<0.5$ bar) indicates a strong interaction between hydrogen molecules and their respective frameworks. We calculated the isosteric heats of hydrogen adsorption for $\mathrm{Cu}-\mathrm{BDC}-\mathrm{H} 225$, Cu-TDC-FD and Cu-FDC-FD using the ClausiusClapeyron equation with $0.2 \mathrm{wt} \%$ of hydrogen uptake capacity at $77 \mathrm{~K}$ and $100 \mathrm{~K}$ (Fig. S14 $\dagger$ ). Isosteric heats of hydrogen adsorption of 7.0, 9.2 and $7.5 \mathrm{~kJ} \mathrm{~mol}^{-1}$ were found for $\mathrm{Cu}-\mathrm{BDC}-\mathrm{H} 225$, $\mathrm{Cu}$-TDC-FD and Cu-FDC-FD, respectively. These values are higher than what is found for most carboxylate-bridged frameworks (3.5-6.5 kJ mol$\left.{ }^{-1}\right)$ with high surface areas. ${ }^{17}$

Enhancing the isosteric heat of hydrogen adsorption for porous materials is an effective way to improve their hydrogen storage performance under mild conditions at near-room temperature or low pressures. In general, the isosteric heat of hydrogen adsorption can be improved by introducing open metal sites, reducing the pore size and so on. ${ }^{18}$ The presence of open $\mathrm{Cu}$ sites can explain the high isosteric heat of hydrogen adsorption for Cu-BDC-H225. Open $\mathrm{Cu}$ sites could be formed during the heating step by releasing the coordinating DMF molecules, which is indicated by the lack of a DMF $v(\mathrm{CO})$ band (Fig. S10 $\dagger$ ). The low nitrogen content of $0.23 \%$ (corresponding to $1.2 \mathrm{wt} \%$ of DMF) is in agreement with this statement. The theoretical value would be $4.66 \%$ and correspond to $24.3 \mathrm{wt} \%$ of DMF and is based on the formulae $\mathrm{Cu}(\mathrm{BDC})(\mathrm{DMF})$. The low heat of hydrogen adsorption (2.2 $\mathrm{kJ} \mathrm{mol}^{-1}$ ) further substantiates our explanation for Cu-BDC-SE(EtOH), which showed a DMF content of $24.8 \mathrm{wt} \%$, a value comparable to the theoretical calculated value (Fig. S10D $\dagger$ ). The high isosteric heats of hydrogen adsorption for $\mathrm{Cu}$-TDC-FD and Cu-FDC-FD cannot be explained by the interaction between hydrogen with open metal sites because there is no evidence of the presence of open copper sites in $\mathrm{Cu}-\mathrm{TDC}-\mathrm{FD}$ and $\mathrm{Cu}-\mathrm{FDC}-\mathrm{FD}$, as indicated by the presence of nitrogen $(\mathrm{N})$ for $\mathrm{Cu}-\mathrm{TDC}-\mathrm{FD}$ and the high hydrogen $(\mathrm{H})$ content for Cu-FDC-FD (elemental analysis results, Table 1). The pore size is likely to play a determining role in the lowpressure hydrogen adsorption behaviour of $\mathrm{Cu}$-TDC and $\mathrm{Cu}$-FDC. Therefore, the pore sizes of $\mathrm{Cu}$-TDC and Cu-FDC were determined using PLATON. ${ }^{9}$ The results reveal that the pore sizes of $\mathrm{Cu}$-TDC and $\mathrm{Cu}-\mathrm{FDC}$ are mainly in the range of $5.4 \AA$ to $8.0 \AA$ A It is believed that the ideal pore size of porous materials for hydrogen adsorption is $6-7 \AA$, which results in an optimal interaction between the $\mathrm{H}_{2}$ molecules and the framework, thus maximizing the total van der Waals forces acting on $\mathrm{H}_{2} \cdot{ }^{19}$ Moreover, the isosteric heat of hydrogen adsorption for $\mathrm{Cu}$-TDC is higher than that for Cu-FDC. Considering the different heteroatoms in their structures, we propose that the stronger polarizability of the thiophene ring contributes to the higher isosteric heat of hydrogen adsorption for Cu-TDC. A similar explanation was proposed by the Yaghi group for IRMOF-20 (constructed from thieno[3,2- $b]$ thiophene-1,5-dicarboxylate).$^{20}$

\section{Conclusions}

In summary, a series of Cu-based coordination polymers composed of ligands with different exocyclic bond angles were synthesized. The results revealed that the exocyclic bond angle plays only a minor role in the construction of the 
structural architecture in this series. Cu- $m$-BDC showed a poor hydrogen uptake capacity because its structure is destabilized during the activation procedure. The all para-substituted analogue, Cu-BDC-H225, showed a hydrogen uptake of $1.22 \mathrm{wt} \%$ (at $77 \mathrm{~K}$ and $1 \mathrm{bar}$ ) despite the fact that the framework exhibits a low surface area of $248 \mathrm{~m}^{2} \mathrm{~g}^{-1}$. The high isosteric heat of hydrogen adsorption for Cu-BDC-H225 $\left(7.0 \mathrm{~kJ} \mathrm{~mol}^{-1}\right)$ and high hydrogen uptake can be explained by the presence of open metal sites. The furan and thiophene analogues, i.e. Cu-FDC and $\mathrm{Cu}$-TDC, display comparable low surface areas $\left(\sim 300 \mathrm{~m}^{2} \mathrm{~g}^{-1}\right)$ and their hydrogen uptake capacities are 0.64 and $0.75 \mathrm{wt} \%$ at $77 \mathrm{~K}$ and 1 bar. Both coordination polymers display unusually high isosteric heats of hydrogen adsorption, i.e. 7.5 and $9.2 \mathrm{~kJ} \mathrm{~mol}^{-1}$ for Cu-FDC and Cu-TDC, respectively. There is no evidence for open metal sites. The high isosteric heats of hydrogen adsorption and the hydrogen uptake can be attributed to an optimal pore size (5.4-8 $\AA$ ) of the said frameworks and the polarizability of the thiophene and furan building blocks.

\section{Acknowledgements}

We gratefully acknowledge financial support from the NWO ACTS Sustainable Hydrogen Programme (project no. 05361017).

\section{Notes and references}

1 (a) S. Kitagawa, R. Kitaura and S. Noro, Angew. Chem., Int. Ed., 2004, 43, 2334; (b) G. Terey, Chem. Soc. Rev., 2008, 37, 191.

2 M. Eddaoudi, D. B. Moler, H. Li, B. Chen, T. M. Reineke, M. O'Keeffe and O. M. Yaghi, Acc. Chem. Res., 2001, 34, 319.

3 (a) L. J. Murray, M. Dinca and J. R. Long, Chem. Soc. Rev., 2009, 38, 1294; (b) M. B. Lalonde, R. B. Getman, J. Y. Lee, J. M. Roberts, A. A. Sarjeant, K. A. Scheidt, P. A. Georgiev, J. P. Embs, J. Eckert, O. K. Farha, R. Q. Snurr and J. T. Hupp, CrystEngComm, 2013, 15, 9408.

4 (a) O. Z. Yesilel, I. Ilker, M. S. Soylu, C. Darcan and Y. Süzen, Polyhedron, 2012, 39, 14; (b) Z. Chen, Y. Zuo, X. Li, H. Wang, B. Zhao, W. Shi and P. Cheng, J. Mol. Struct., 2008, 888, 360; (c) P. J. Calderone, D. Banerjee, A. C. Santulli, S. S. Wonga and J. B. Parise, Inorg. Chim. Acta, 2011, 378, 109.

5 Y. H. Hu and L. Zhang, Adv. Mater., 2010, 22, E117.

6 Bruker. SAINT-Plus, Bruker AXS Inc., Madison, Wisconsin, USA, 2001.

7 G. M. Sheldrick, SADABS and TWINABS: Area-Detector Absorption Correction, v2.10, Universität Göttingen, Germany, 1999.

8 G. M. Sheldrick, Acta Cryst., 2008, A64, 112.

9 A. L. Spek, Acta Cryst., 2009, D65, 148.

10 A. J. M. Duisenberg, L. M. J. Kroon-Batenburg and A. M. M. Schreurs, J. Appl. Crystallogr., 2003, 36, 220.

11 A. M. M. Schreurs, X. Xian and L. M. J. Kroon-Batenburg, J. Appl. Crystallogr., 2010, 43, 70.

12 M. Eddaoudi, J. Kim, J. B. Wachter, H. K. Chae, M. O'Keeffe and O. M. Yaghi, J. Am. Chem. Soc., 2001, 123, 4368.

13 M. Eddaoudi, J. Kim, D. Vodak, A. Suidik, J. Wachael, M. O'Keeffe and O. M. Yaghi, Proc. Natl. Acad. Sci. U. S. A., 2002, 99, 4900.

14 C. G. Carson, K. Hardcastle, J. Schwartz, X. Liu, C. Hoffmann, R. A. Gerhardt and R. Tannenbaum, Eur. J. Inorg. Chem., 2009, 2338.

15 CCDC 956646-956648 contain the supplementary crystallographic data for this paper. These data can be obtained free of charge from The Cambridge Crystallographic Data Centre via www.ccdc.cam.ac.uk/data_request/cif.

16 (a) M. Sabo, A. Henschel, H. Frode, E. Klemm and S. Kaskel, J. Mater. Chem., 2007, 17, 3827; (b) A. G. Wong-Foy, A. J. Matzger and O. M. Yaghi, J. Am. Chem. Soc., 2006, 128, 3494.

17 D. Zhao, D. Yuan and H.-C. Zhou, Energy Environ. Sci., 2008, 1, 222.

18 (a) J. L. C. Rowsell and O. M. Yaghi, Angew. Chem., Int. Ed., 2005, 44, 4670; (b) M. Hirscher, B. Panella and B. Schmitz, MicroporousMesoporous Mater., 2010, 129, 335; (c) R. Zou, A. I. Abdel-Fattah, H. Xu, A. Y. Zhao and D. D. Hickmott, CrystEngComm, 2010, 12, 1337.

19 S. Ma and L. Meng, Pure Appl. Chem., 2011, 83, 167.

20 J. L. C. Rowsell and O. M. Yaghi, J. Am. Chem. Soc., 2006, 128, 1304. 